\title{
Kinetic Modelling of Individual Starch Granules Swelling
}

\author{
Arnesh Palanisamy ${ }^{\mathrm{a}}$, François Deslandes ${ }^{\mathrm{b}}$, Marco Ramaioli $^{\mathrm{a}}$, Paul Menut ${ }^{\mathrm{a}}$, Artemio \\ Plana-Fattori ${ }^{\mathrm{a}}$, Denis Flick ${ }^{\mathrm{a}, *}$ \\ ${ }^{a}$ Université Paris Saclay, INRAE, AgroParisTech, UMR SayFood, 91300, Massy, France \\ ${ }^{b}$ Université Paris Saclay, INRAE, AgroParisTech, UMR MaIAGE, 78350, Jouy-en-Josas, France
}

\begin{abstract}
A novel kinetic model is proposed for individual starch granule swelling based on swelling kinetics time series data. The data was acquired from time-lapse microscopy observations of starch granules in a dilute suspension and subsequent image analysis. Chemically modified waxy-maize starch was used. The size evolution of many granules when subjected to various hydro-thermal treatments on a temperature-controlled stage was determined. Observations showed that swelling is not an instantaneous process and varies from a granule to another. A model has been developed which takes into account the effect of temperature evolution and variability between the granules on their swelling. This model can contribute to robust multi-scale simulation of industrial processes involving starch suspensions.
\end{abstract}

Keywords: Starch Granule, Image analysis, Swelling kinetics, Time-series data, Modelling

\section{Introduction}

Starch is the predominant food reserve in plants and provides $70-80 \%$ of the calories 3 consumed by humans worldwide in various forms of food products (Bertolini, 2010). In 4 2000, the world starch production was estimated to be around 48.5 million tons, including 5 native and modified starches. Hence, starch has been a perennial subject of research through 6 decades. Starch granules majorly consists of two polymers: amylose and amylopectin. Both amylose and amylopectin have $\alpha$-glucose as the monomer, however, their difference arises

\footnotetext{
*corresponding author

Email address: denis.flick@agroparistech.fr (Denis Flick)
} 
from their linkages. Amylose has $\alpha(1-4)$ and is linear whereas amylopectin has $\alpha(1-6)$ and is highly branched. The ratio of amylose and amylopectin in the starch granule depends on its source and botanical origin. This in turn has drastic consequences on the physical properties such as rheology (Banks et al., 1974; Hoover, 2001; Srichuwong et al., 2005; Visser et al., 1997). Molecular properties such as molecular weight distribution and degree of amylopectin branching are also known to impact the functional attributes at the macro-scale (Blennow et al., 2001; Fredriksson et al., 1998; Singh et al., 2007).

Gelatinization is the process in which starch granules undergo an irreversible transformation when subjected to thermomechanical treatment in the presence of water. During this process starch granules swell by imbibing water and increase the overall viscosity of the suspension. It is also sometimes referred to as starch pasting in literature. Starch granules are semi-crystalline with concentric rings of crystalline and amorphous phases (Ratnayake and Jackson, 2008). On the microscopic scale, the process corresponds to the melting of crystallites, loss of birefringence, leaching of amylose into the continuous phase and sometimes rupture of the granular structure (Atwell, 1988; Biliarderis, 1992). During gelatinization, melting of crystalline region in the granule occurs and depending on the origin of the starch, the range for this transition is between 60 and $70{ }^{\circ} \mathrm{C}$ (Slade and Levine, 1995). The evolution of viscosity during gelatinization is also influenced by the process parameters such as concentration, shear rate, thermal history, $\mathrm{pH}$ and presence of other ingredients (Thomas and Atwell, 1999; Malumba et al., 2018). For high amylopectin cereal starches such as waxy maize starch, the granules tend to hydrate with ease, swell rapidly and rupture to a great extent which results in loss of paste viscosity. The rupture of the granules can be avoided by chemically modifying the starch. This involves cross-linking via chemical bonds that act as bridges between the two macromolecules. The introduction of functional groups into the starch molecules such as acetylation results in lower amylose leaching properties of starch. The resulting modified starches have markedly altered physicochemical properties (Ashogbon and Akintayo, 2014). Waxy maize starch is used in a wide variety of applications in the food industry owing to its stability (Tattiyakul and Rao, 2000).

The sensory perception of viscosity is an important mouthfeel sensation (Szczesniak, 
1963; Wood, 1968). Starch is used as a viscosity enhancer in many food formulations. Hence, it is critical to accurately predict viscosity changes both from a product development standpoint and an engineering design standpoint. During the thermal processing of liquid food product containing starch, viscosity changes must be known to accurately estimate process variables as the process is highly coupled in terms of heat transfer, momentum transfer and transformation (Plana-Fattori et al., 2016). This warranted decades of research into the sole aspect of viscosity predictions and significant literature exist regarding the chief aspects which dictate the same. They are (a) the suspending medium's viscosity $\eta_{0}$, (b) the granule's volume fraction $\phi$, (c) the granule's deformability, and (d) the imposed shear rate (Chen et al., 2007). Nayouf et al. (2003) indicated that volume fraction of granules can be estimated if the mean granule size $\left(D_{t}\right)$ can be accurately determined.

Increasingly researchers started defining progress of gelatinization in terms of the increase in diameter of granules (Anuntagool et al., 2017; Okechukwu and Rao, 1996; Bagley and Christianson, 1982; Bakshi and Singh, 1980; Suzuki et al., 1976; Doublier et al., 1987; Kokini et al., 1992). Alternate methods used to define gelatinization are based on DSC, rheology or birefringence (Cui et al., 2014; Choi and Kerr, 2004; Dolan and Steffe, 1990; Biliaderis and Prokopowich, 1994; Chang and Liu, 1991; I'anson et al., 1990; Kohyama and Nishinari, 1991; Miles et al., 1985; Slade and Levine, 1991). However these are all equivalent indications of the same process. Granule swelling occurs in two phases, first is the hydration phase where there is a slight reversible increase in the diameter of the granules typically occurring in the temperature range $30-60{ }^{\circ} \mathrm{C}$ and a second irreversible phase where there is a large increase in diameter occurring at temperatures above $60{ }^{\circ} \mathrm{C}$ (Okechukwu and Rao, 1996). Some authors reported that mean size and size distribution of swollen granules were correlated with suspension consistency and flow behavior index (Okechukwu and Rao, 1996; Steeneken, 1989; Evans and Lips, 1990). Thus, there have been multiple attempts at kinetic modelling this phenomena to predict the particle size evolution.

Kubota et al. (1979) attempted to model this phenomena with Arrhenius law and proposed a first order kinetic equation with respect to non-dimensionalised consistency index. Okechukwu and Rao (1995) introduced a similar rate equation with another dimensionless 
variable called extent of gelatinization based on mean particle diameter of the population. Lagarrigue et al. (2008) used the same formulation but argued that the reaction is second order. Krüger et al. (2003) proposed a kinetic model which suggest the rate of increase in diameter is proportional to the inverse of the mean diameter of the population diameter with Arrhenius behavior and reaching a plateau at maximum diameter. Some authors also suggested a set of reactions to describe gelatinization (Kokini et al., 1992). Malumba et al. (2013) compared a wide range of rate expressions (Nth order kinetic, Diffusional, Phase boundary and Avrami-Erofeev) to predict the isothermal swelling kinetics at different temperatures and showed that the predictability was best for Nth order reaction models especially second order and third order. They concluded that starch granule gelatinization is not a simple water diffusion or a boundary phenomenon. The heat transferred inside the granules induces phenomena such as melting of the crystallite, interaction between carbohydrate polymers. This includes inter-chain and intra-chain polymer folding and hydrogen bonding proceeding with semi-cooperative swelling of granules. They also argued that activation energy reported in literature must be called apparent activation energy as the same, changed based on the form and order of the rate equation assumed. Plana-Fattori et al. (2016) have used a modified form of rate constant with a cutoff minimum temperature instead of the traditional Arrhenius form, which they substantiated with experiments.

All the above-mentioned works have always been attempts to model the swelling kinetics of the population mean but not at the individual granule scale. Desam et al. (2018) tried to model the swelling of a single granule based on diffusion kinetics and Flory-Huggins theory of polymer mixing, but the model assumes all granules to have similar cross-links, tortuosity, and elastic restoring force. In this work, we propose a novel kinetic modeling at the individual granule scale rather than the population mean. Time-series data obtained from image processing of hot stage coupled microscope time-lapse images was used for building and fitting the model. This model captures the inter granule variability of starch swelling in water. This variability has not been quantified and addressed adequately in the previous modeling works. We try to capture these nuances in this work albeit it empirically and thus the parameters obtained are valid for chemically stabilized cross-linked waxy maize 
starch (acetylated distarch adipate, C*Tex 06205), provided by Cargill (Baupte, France). The method developed here enables modeling at the granular scale allowing one to capture the dynamics better for multi-scale modeling translating into wide-reaching consequences in plant equipment design, optimization, differentiated product development, simulation, robust process development and robust model based process control systems.

\section{Materials and methods}

\subsection{Experimental method}

Chemically stabilized cross-linked waxy maize starch ( $\mathrm{C}^{*}$ Tex 06205), provided by Cargill (Baupte, France), cross-linked via adipates, was used in $0.5 \mathrm{~g} \cdot \mathrm{kg}^{-1}$ suspensions of starch in water. This starch is composed of $99 \%$ of amylopectin and less than $1 \%$ of amylose. This type of starch does not lead to disruption and no release of amylose content is expected. In terms of functionality, it has notably a good resistance to shear forces, a good storage stability and a high paste clarity. The suspension was preheated to $50^{\circ} \mathrm{C}$ under gentle stirring with a magnetic pellet. Using a dropper sampling was performed and sample was transferred to the microscopic glass slides with adhesive spacers of $250 \mu \mathrm{m}$. Samples were observed under 50X magnification using an Olympus BX-51 microscope (Olympus Optical Co. Ltd., Tokyo, Japan). Images were acquired using a Basler A102fc digital camera (Basler AG, Ahrensburg, Germany). Each observation is an 8 bit image of $1388 \times 1038$ pixels which represents a $361 \times 270 \mu \mathrm{m}^{2}$ area. Microscope glass slides with samples were placed on a Linkam LTS120 stage (Linkam Scientific Instruments, Surrey, UK). The temperature was controlled with the Linksys32 software. The samples were subjected to different temperature profiles, starting with a holding at $50{ }^{\circ} \mathrm{C}$ for $1 \mathrm{~min}$ (figure 1a). Some samples were observed under the microscope at different constant temperatures from $55{ }^{\circ} \mathrm{C}$ to $62{ }^{\circ} \mathrm{C}$ for 1 hour; no image processing was carried out for these experiments as the objective of the same was only to observe if the granules began to swell and to estimate the latency time before swelling. 


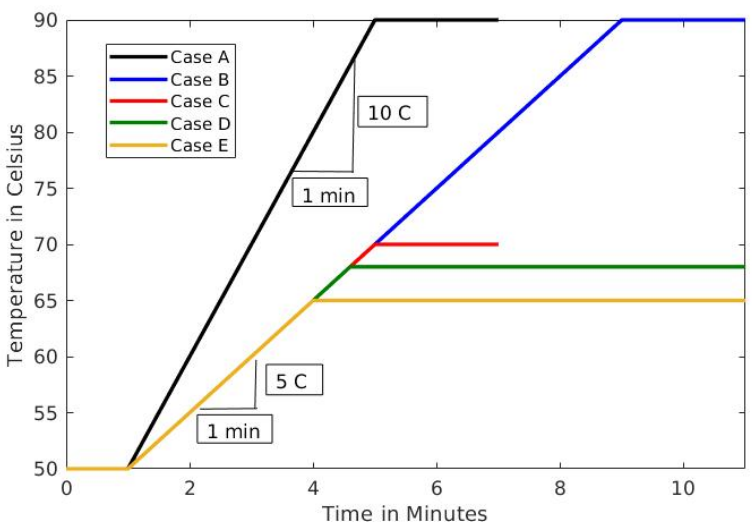

(a) Temperature profiles of Case A to E

\subsection{Image data analysis and notation}

$$
D=\sqrt{M m} .
$$

The Java plugin for ImageJ software developed by Deslandes et al. (2019) was used to process the images. Ferret diameter is a length of an object measured along a specified direction. Thus, along different direction we have different Ferret lengths. We note the minimum and maximum Ferret diameter of a granule $(\mu \mathrm{m}), \mathrm{m}$ and $\mathrm{M}$ respectively. The diameter of the granule is taken as the geometric mean of the Ferret lengths:

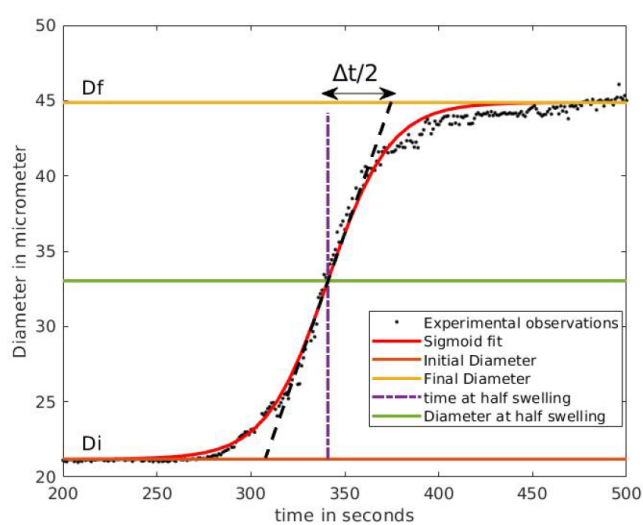

(b) Sigmoid fitting time series swelling data

Figure 1

Image analysis and subsequent sigmoid curve fitting for the resulting time series data of diameter as a function of time was done following the procedure outlined in Deslandes et al. (2019). The parameters $D_{i}, D_{f}, \delta$ and $t_{1 / 2}$ denote the initial diameter $(\mu \mathrm{m})$, the final diameter $(\mu \mathrm{m})$, the swelling rate $\left(s^{-1}\right)$ and the half-swelling time $(\mathrm{s})$ of the granule respectively. These morphological and kinetics parameters are estimated by performing least-squares fitting on the size evolution data obtained from the image processing onto the sigmoid curve given by equation 2 (Deslandes et al., 2019). A typical diameter evolution of a granule with time along the least square fitting of the sigmoid curve is depicted in figure $1 \mathrm{~b}$.

$$
\widetilde{D}(t)=\frac{D_{f}-D_{i}}{1+e^{-\delta\left(t-t_{1 / 2}\right)}}+D_{i}
$$


The beginning of the 1 minute hold time at $50{ }^{\circ} \mathrm{C}$ is taken as the origin of time and different temperature profiles as depicted in the figure 1a are imposed on the sample. The individual granule swelling duration $(\Delta \mathrm{t})$ is estimated by extrapolation of the tangent at the half-swelling time. It can be calculated from the parameter $\delta$ using the following equation:

$$
\Delta t=\frac{4}{\delta} .
$$

We then define $t_{\text {onset }}$, the individual swelling onset time by

$$
t_{\text {onset }}=t_{1 / 2}-\frac{\Delta t}{2} .
$$

\section{Experimental results and observation}

\subsection{Observation at constant temperature between $55^{\circ} \mathrm{C}$ and $62^{\circ} \mathrm{C}$}

Observing the samples under the microscope at different constant temperatures starting from $55{ }^{\circ} \mathrm{C}$ to $62{ }^{\circ} \mathrm{C}$ for 1 hour was the objective to determine the minimum temperature at which swelling starts. It was observed as shown in images of figure 2 , the gradual increase in fraction of granules swollen as temperature increases from $57{ }^{\circ} \mathrm{C}$ to $62{ }^{\circ} \mathrm{C}$. We can safely say that it required at least around $60{ }^{\circ} \mathrm{C}$ to observe swelling in majority of the granules, this is consistent with the literature reported values (Slade and Levine, 1995). However, this may not be entirely true as we saw some granules swell at $58^{\circ} \mathrm{C}$ and some granules not swollen at $62{ }^{\circ} \mathrm{C}$ even after a duration of 1 hour. Nevertheless, in industrial processes, the maximal temperature is always much greater than $70{ }^{\circ} \mathrm{C}$ and residence time in heat exchangers is of some minutes only. In light of the practicality and the relevance to the industrial process, we make this assumption that the minimum swelling temperature is of $60{ }^{\circ} \mathrm{C}$ for all the granules.

For the experiments carried for 1 hour ( 1 image per 5 seconds) at $62{ }^{\circ} \mathrm{C}$, the latency time in the onset of swelling was manually noted from the diameter vs time data obtained after post processing using the plugin developed by Deslandes et al. (2019). Figure 3 shows the experimental cumulative distribution (47 granules) and an exponential curve fit for the same. 


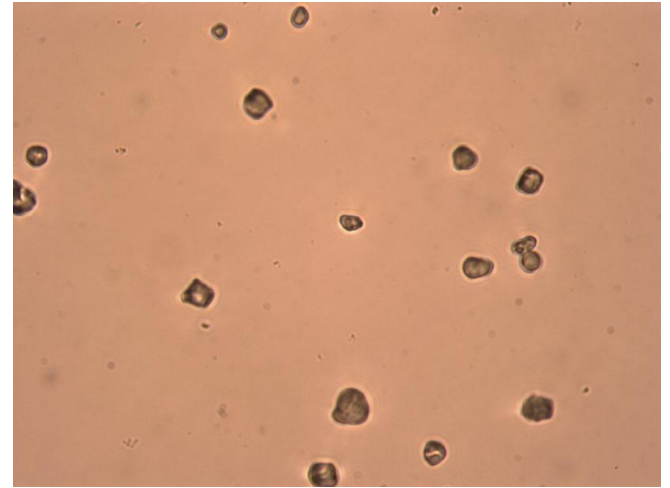

(a) $57^{\circ} \mathrm{C}$ Temperature, image at time 0 seconds.

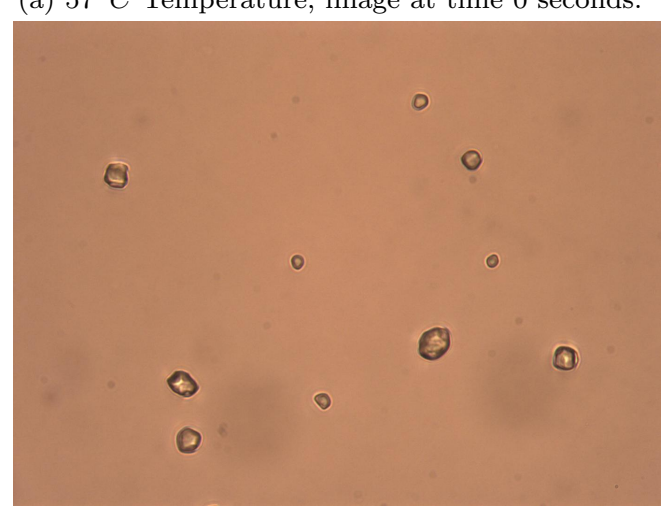

(c) $60^{\circ} \mathrm{C}$ Temperature, image at time 0 seconds.

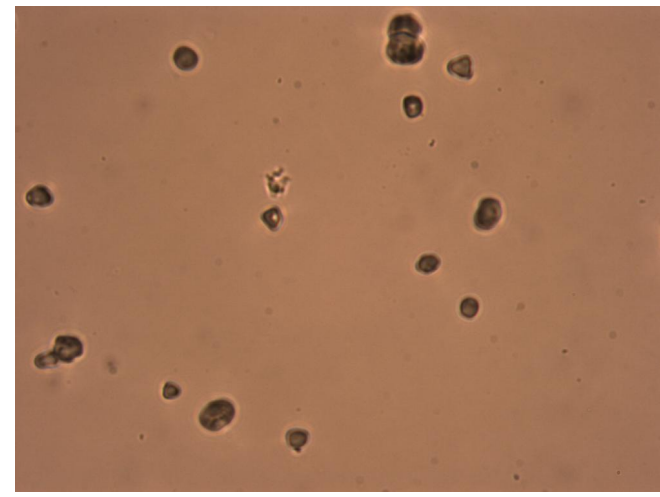

(e) $62^{\circ} \mathrm{C}$ Temperature, image at time 0 seconds.

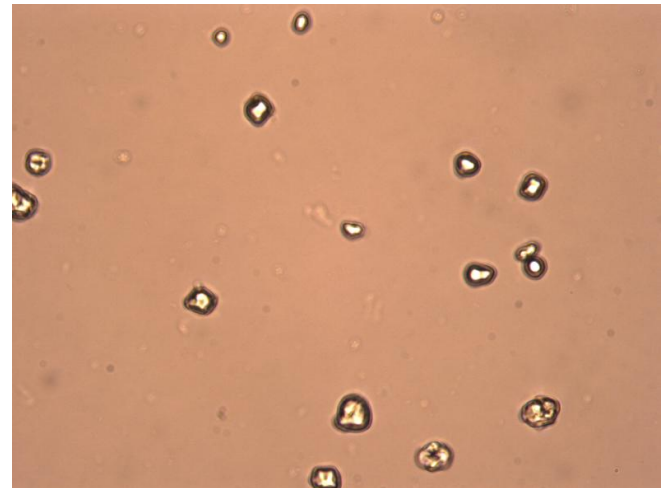

(b) $57^{\circ} \mathrm{C}$ Temperature, image at time $1 \mathrm{hr}$.

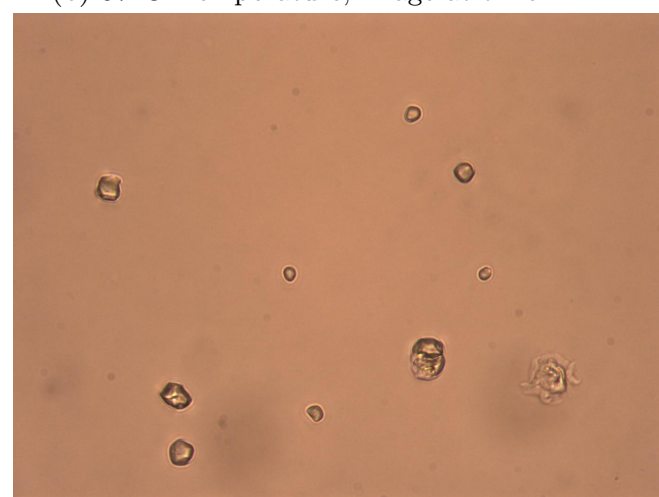

(d) $60^{\circ} \mathrm{C}$ Temperature, image at time $1 \mathrm{hr}$.

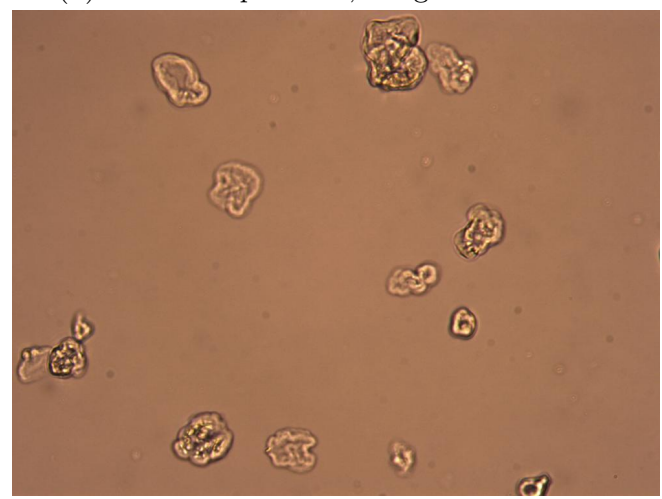

(f) $62^{\circ} \mathrm{C}$ Temperature, image at time $1 \mathrm{hr}$.

Figure 2: Starch granules at the beginning and after 1 hour at different temperatures

We use this information in the section 4.1 to justify the choice of mathematical formulation.

\subsection{Diameter increase during temperature ramp}

The results of the image processing and data analysis during different temperature ramps are summarized in the table 1 . Note that for the case $\mathrm{E}$ with maximum temperature $65^{\circ} \mathrm{C}$ only the completely swollen granules were used to compute the sigmoid curve parameters. 


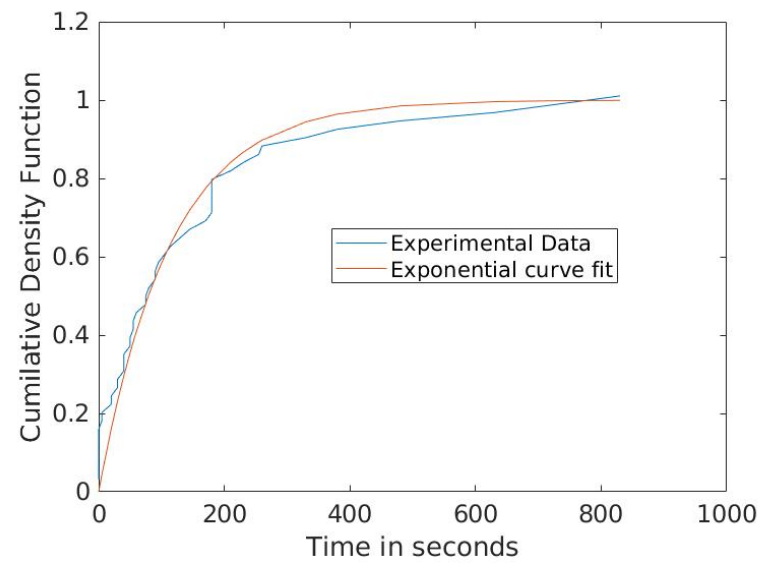

Figure 3: Experimental delay times for swelling onset at $62{ }^{\circ} \mathrm{C}$

All the reported cases had a lapse rate of 1 image per second. The onset times reported here are from the beginning of the 1 min hold time at $50{ }^{\circ} \mathrm{C}$.

\begin{tabular}{|c|l|l|l|l|c|c|c|c|c|c|}
\hline Case & $T_{\max }\left({ }^{\circ} \mathrm{C}\right)$ & $\begin{array}{l}\text { ramp } \\
\text { rate } \\
\left({ }^{\circ} \mathrm{C} / \mathrm{min}\right)\end{array}$ & $\begin{array}{l}\text { hold } \\
\text { time } \\
(\mathrm{min})\end{array}$ & $\begin{array}{l}\text { Number } \\
\text { of gran- } \\
\text { ules }\end{array}$ & \multicolumn{2}{|l|}{$t_{\text {onset }}(\mathrm{s})$} & \multicolumn{2}{|l|}{$\Delta t(\mathrm{~s})$} & \multicolumn{2}{|l|}{ Df/Di } \\
\hline & & & & & mean & std & mean & std & mean & std \\
\hline $\mathrm{A}$ & 90 & 10 & 2 & 163 & 180 & 18 & 29 & 21 & 2.30 & 0.32 \\
$\mathrm{~B}$ & 90 & 5 & 2 & 142 & 276 & 34 & 65 & 46 & 2.36 & 0.33 \\
$\mathrm{C}$ & 70 & 5 & 2 & 48 & 274 & 44 & 51 & 34 & 2.38 & 0.43 \\
$\mathrm{D}$ & 68 & 5 & 15 & 41 & 250 & 37 & 98 & 92 & 2.35 & 0.25 \\
$\mathrm{E}$ & 65 & 5 & 15 & 42 & 293 & 122 & 300 & 169 & 2.07 & 0.49 \\
\hline
\end{tabular}

Table 1: Summary of Experimental conditions and swelling data with sigmoid fits

Equation 5 defines the degree of swelling parameter which is used to track the swelling of an individual granule.

$$
S(t)=\frac{D(t)-D_{i}}{D_{f}-D_{i}}
$$

Thus, $\mathrm{S}(\mathrm{t})$ ranges from 0 to 1 , where 0 corresponds to no swelling and 1 corresponds to complete swelling. To obtain the dimensionless variable $\mathrm{S}$ as function of time for each granule, $D_{i}$ and $D_{f}$ obtained from the sigmoid fitting are used. Thus one can obtain cloud plots of the non-dimensional diameter evolution for each of the experimental cases shown in figure 1a. The noise observed in the plots of dimensionless variable $\mathrm{S}$ is the direct result 
of noise in the diameter of granule estimated through image processing (Deslandes et al., 2019).

From the figure 4 and table 1 it can be concluded that for a given temperature evolution all granules do not begin to swell at the same time. In fact, there is a latency time or delay in onset time involved in the process. The value of this latency time decreases with increase in temperature and varies from granule to granule as seen from the cloud plots in figure 4 . Latency time does not depend on the diameter of the granules (Deslandes et al., 2019) and it approximately follows an exponential distribution at a constant temperature as seen in figure 3. It is also observed from figure 4 that granules with high latency time swell less rapidly than the ones with low latency times.

Granule diameter reaches a constant value given sufficient time and temperature. Individual granule characteristics and temperature profile determine the magnitude of time required to achieve this constant value. The ratio of the final diameter to the initial diameter or simply known as the ratio of swelling $\left(D_{f} / D_{i}\right)$ varies from granule to granule. This is also reported by Deslandes et al. (2019). The mean ratio of swelling practically is almost independent of the temperature history and initial diameter. This is in accordance with mechanistic models (e.g. (Desam et al., 2020; Briffaz et al., 2014; Watanabe et al., 2001, 2007)) in which the final state corresponds to an equilibrium in which the water demand reaches zero. We also did not observe any significant correlation between latency times and swelling ratio $\left(D_{f} / D_{i}\right)$ based on our data. From table 1 for temperatures above $68{ }^{\circ} \mathrm{C}$ we have nearly constant ratio of swelling around 2.35 but for lower temperature of $65^{\circ} \mathrm{C}$, the ratio decreases suggesting partial swelling. However, as mentioned in industrial process the temperature used is higher to ensure complete swelling state i.e. swelling ratio of 2.35 in this case. As reported by Deslandes et al. (2019) the ratio of swelling approximately follows a truncated normal distribution.

These observations were used to develop a novel model that captures most of the essential features, which is discussed in detail in the next section. 


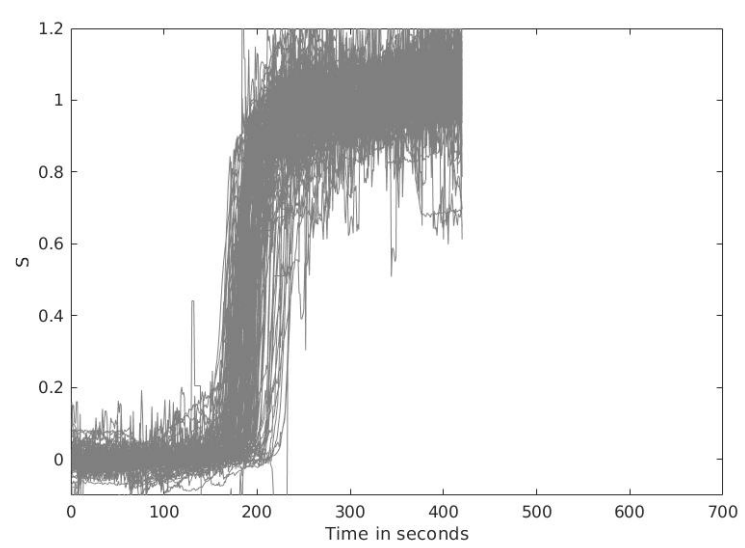

(a) Case A

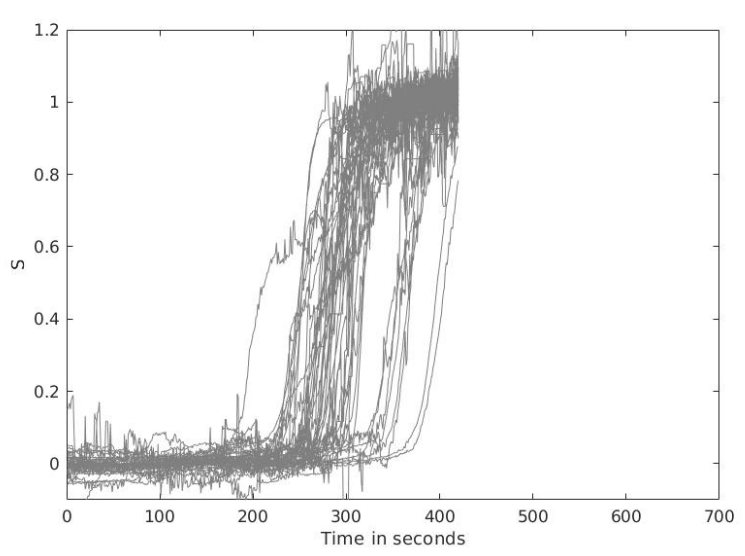

(c) Case C

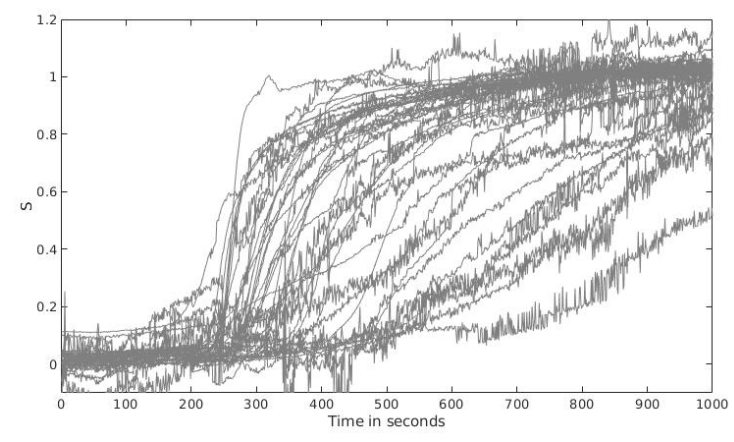

(e) Case E

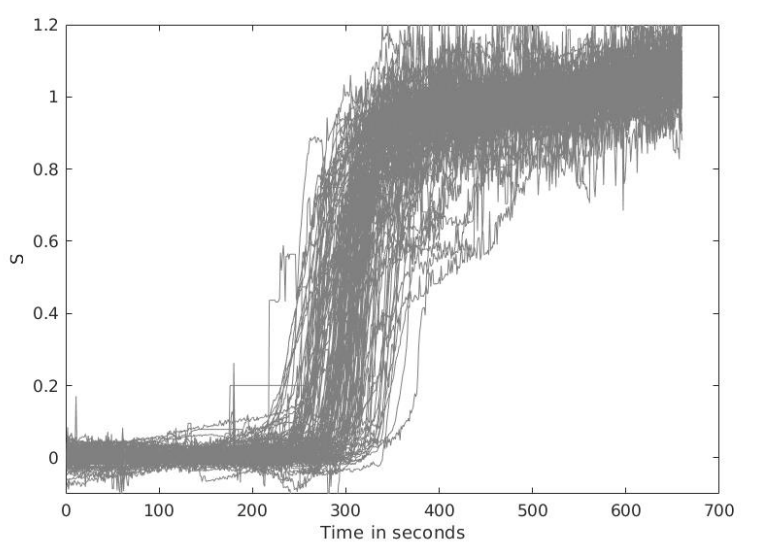

(b) Case B

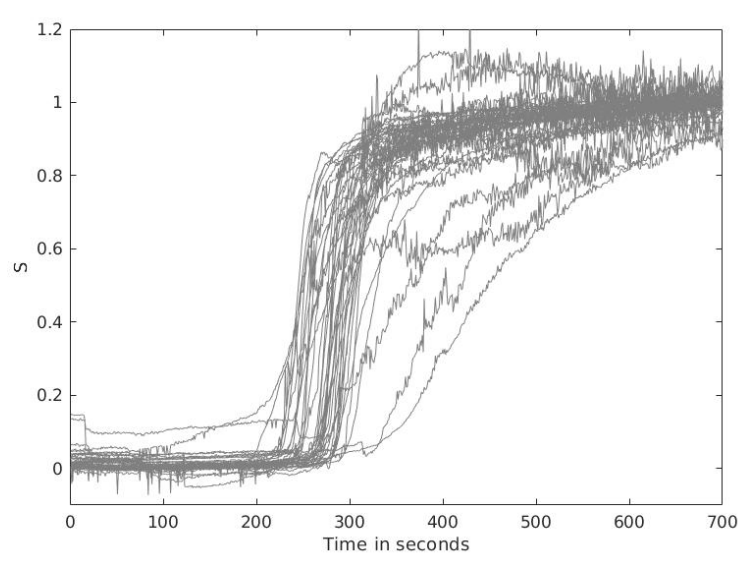

(d) Case D

Figure 4: Non dimensional diameter evolution 


\section{Model Formulation and Results}

\subsection{Kinetic model development}

As discussed in the previous section we observed that most granules do not swell at $60{ }^{\circ} \mathrm{C}$ even after 1 hour, so we set the minimum temperature of swelling at $T_{\min }=60{ }^{\circ} \mathrm{C}$ (i.e. below $60{ }^{\circ} \mathrm{C}$ there is no swelling of granules). Based on the microscopic images we observed that each granule has a variable time delay in the onset of swelling which decreases with increase in temperature. To mathematical formulate the same, let at any instant the additional fraction (denoted by $d F$ ) of granules beginning to swell in next time unit be proportional to the fraction of granules that did not begin to swell yet (denoted by $1-F$ ).

In equation form it can be expressed as

$$
d F=\frac{(1-F)}{\tau} d t
$$

$$
\ln (1-F)=-\int_{0}^{t_{\text {onset }}} \frac{d t}{\tau}
$$

Integrating the above requires the knowledge about the characteristic latency time $\tau$ which depends on temperature T. When temperature is constant

$$
F=1-\exp \left(\frac{-t_{\text {onset }}}{\tau}\right) .
$$

Hence in this mathematical formulation we have cumulative density function vs latency time following the exponential function as was observed in figure 3 .

We propose that the characteristic latency time in function of temperature follows:

$$
\tau=\max \left(0,\left(\frac{T_{r e f}-T_{\min }}{T-T_{\min }}\right)\right) \tau_{r e f}
$$

where $T_{r e f}$ is arbitrary fixed at $T_{r e f}=62^{\circ} \mathrm{C}$ and $T_{\min }=60^{\circ} \mathrm{C}$ as indicated previously.

Since there is variability of swelling onset between granules, we introduce a parameter called "difficulty of swelling" parameter $\alpha \in[0,1]$. For a granule, $\alpha$ is selected at random from uniform distribution. Thus during the ramp step of the heat treatment for a granule 
whose difficulty of swelling is $\alpha, t_{\text {onset }}$ is given by equation 10 .

$$
\ln (1-\alpha)=-\int_{0}^{t_{\text {onset }}} \frac{d t}{\tau}=-\int_{0}^{t_{\text {onset }}} \frac{1}{\tau_{\text {ref }}} \max \left(0,\left(\frac{T-T_{\min }}{T_{\text {ref }}-T_{\min }}\right)\right) d t
$$

During the temperature $\operatorname{ramp} T=T_{\min }+\beta \times t$, where $\beta$ is the ramp rate $\left({ }^{\circ} \mathrm{Cs}^{-1}\right)$. Solving equation 10 results in

$$
t_{\text {onset }}-t_{\text {min }}=\left(\frac{-2 \ln (1-\alpha)\left(T_{\text {ref }}-T_{\min }\right) \tau_{r e f}}{\beta}\right)^{1 / 2}
$$

where $t_{\min }$ is the time at which $T=T_{\min }=60^{\circ} \mathrm{C}$.

Once the granule began to swell $\left(t>t_{\text {onset }}\right)$, its diameter increases. A first-order reaction rate is assumed inspired from Kubota et al. (1979), Lund and Lorenz (1984) and Okechukwu and Rao (1995).

$$
\frac{d S}{d t}=K(1-S)
$$

It is assumed the reaction does not proceed below the cut off temperature $T_{\min }$ similar to the previous work by Plana-Fattori et al. (2016).

Kinetics for swelling also did speed up as temperature increased. Hence we propose the following equation 13 :

$$
K=K_{r e f}(1-\alpha)^{0.5}\left(\frac{T-T_{\min }}{T_{\text {ref }}-T_{\text {min }}}\right)^{2}
$$

where $K_{r e f}$ is the rate constant at $T_{r e f}$ for a granule which has no difficulty to swell $(\alpha=0)$.

Thus now one can solve for $\mathrm{S}$ of a granule given the temperature profile. Moreover from Deslandes et al. (2019) we know that $D_{0}$ and $D_{\text {final }} / D_{0}$ follow normal distribution.

\subsection{Calibration of model parameters and model predictions}

Identification of swelling parameters $\tau_{r e f}$ and $K_{r e f}$ was carried out using the $S_{50}$ of the data obtained from Case A described in table 1 and figure 4. Note that for a median granule by definition the value of $\alpha$ is 0.5 . Non-linear fitting of predicted by the model $S_{50}$ with the experimental $S_{50}$ using "fitnlm" function of MATLAB (2018) for the Case A resulted in values $\tau_{r e f}=190 \mathrm{~s}$ and $K_{0}=0.0023 \mathrm{~s}^{-1}$. This means the median latency time at the 
reference temperature of $62{ }^{\circ} \mathrm{C}$ is 132 seconds i.e. nearly 2 minutes.

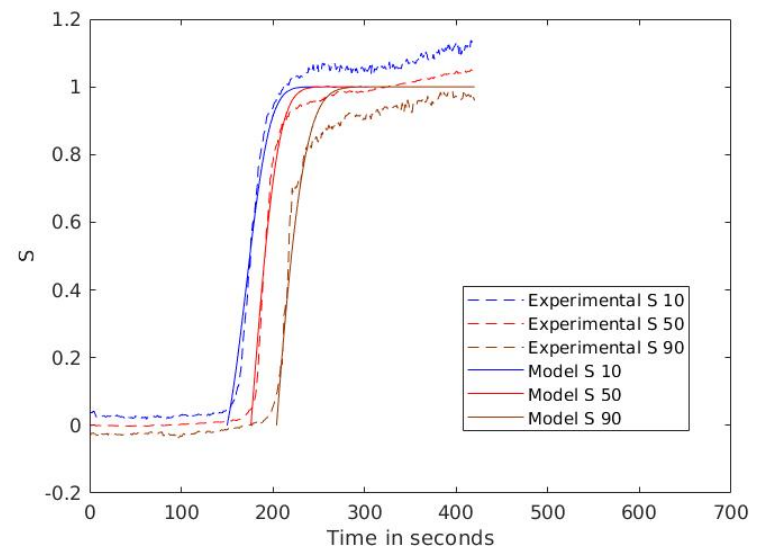

Case A

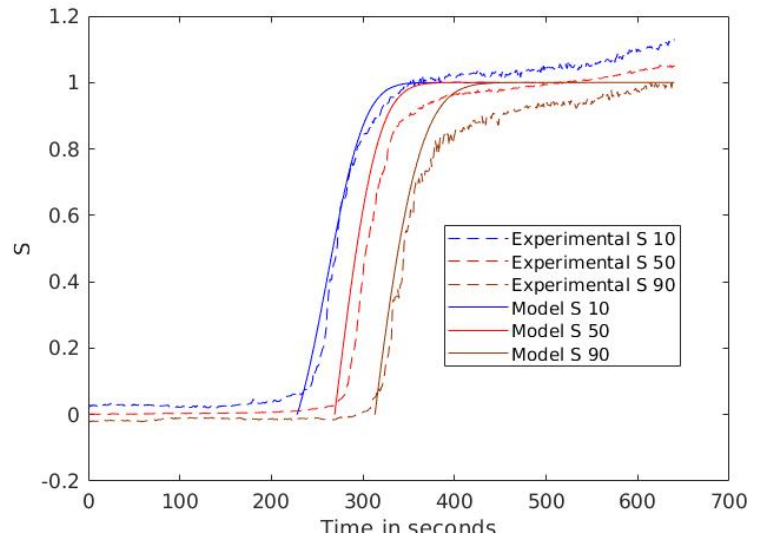

Case B

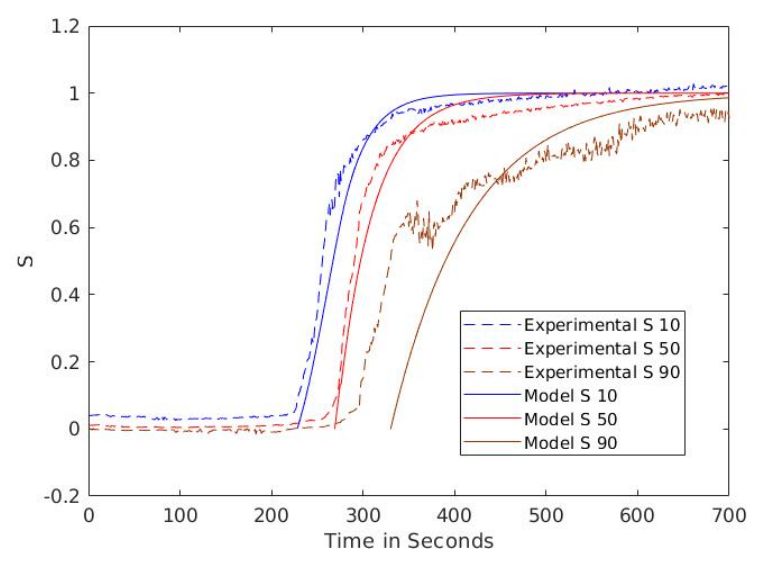

Case D

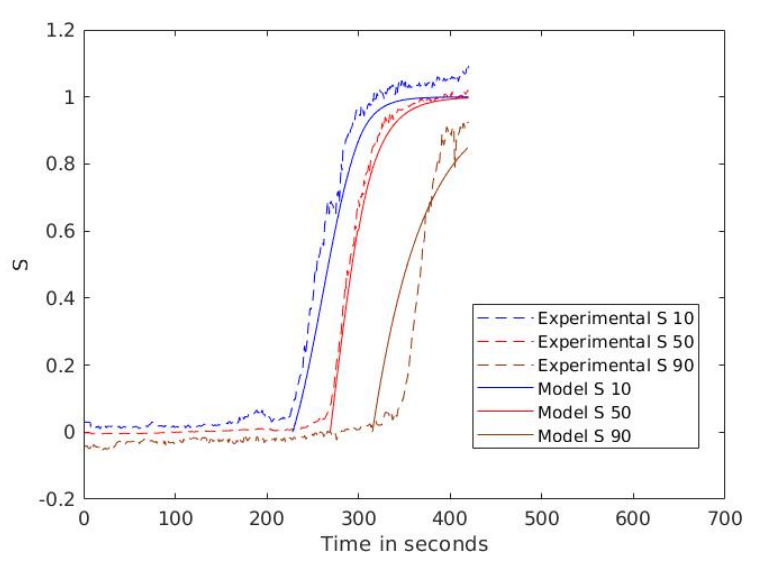

Case C

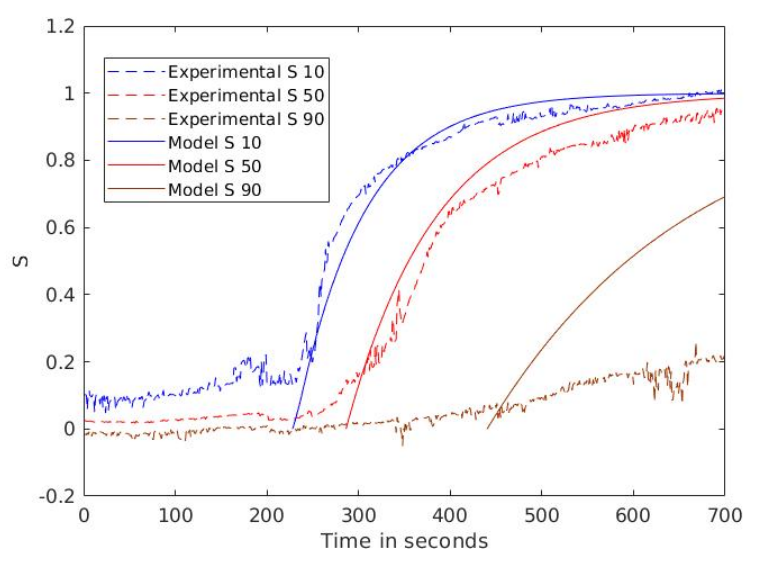

Case E

Figure 5: Model prediction of non dimensional diameter evolution 
Thus now we have a calibrated model. Therefore $S_{10}, S_{50}$ and $S_{90}$ for all the cases can be predicted and compared with the experimental results. Note that the values of alpha for $S_{10}$ and $S_{90}$ are 0.1 and 0.9 respectively as previously explained. In the figure 5 the predictions of $S_{10}, S_{50}$ and $S_{90}$ are shown with respect to the experimental data.

It should be noted that due to the noise in the measurement and the value of $D_{i}$ derived from fitting the sigmoid curve we have $\mathrm{S}$ not beginning exactly at 0 for all the granules at the initial time points. We see the increase in the dispersion between $S_{90}$ and $S_{10}$ progressively from cases A to E. These observations are in-line with the model assumptions that rate constant increase with temperature and latency time decreases with temperature. From the plots in figure 5, we observe that model predictions overall are close approximations of the experimental data. The discrepancy for $S_{90}$ in case of D and E could be due to the limited number of observed granules in this case.

\subsection{Monte Carlo Simulation and results}

Now that sufficient confidence has been established in the kinetic model, we can perform Monte Carlo simulations and predict the population $D_{10}, D_{50}$ and $D_{90}$ evolution. The following parameters listed here were used for the simulation

$$
\begin{aligned}
& T_{r e f}=62^{\circ} \mathrm{C}, T_{\min }=60^{\circ} \mathrm{C}, \\
& \tau_{r e f}=190 \mathrm{~s}, K_{\text {ref }}=0.0023 \mathrm{~s}^{-1}, \text { number of granules } I=1000, \\
& D_{i} \subset \mathcal{N}(14.77 \mu \mathrm{m}, 4.44 \mu \mathrm{m}), D_{f} / D_{i} \subset \mathcal{N}(2.34,0.33),
\end{aligned}
$$

The distributions of $D_{i}$ and $D_{f} / D_{i}$ were calculated from the pool experimental data of cases A to D. Case E was not considered as we see complete swelling did not always occur in this case. For granule initial diameter the normal distribution was used with truncated tails with minimum diameter as $0.25 \times$ mean diameter and maximum value $3 \times$ mean diameter. The ramp rates and hold times were feed into the simulation as per the individual cases as tabulated in table 1. A MATLAB script was written to execute the model, $4^{\text {th }}$ order Range Kutta method was used for integration.

It can be observed in figure 6 that the model predictions are close to the experimental data and the model sufficiently captures the nuances of the process. The slope at the midpoint 


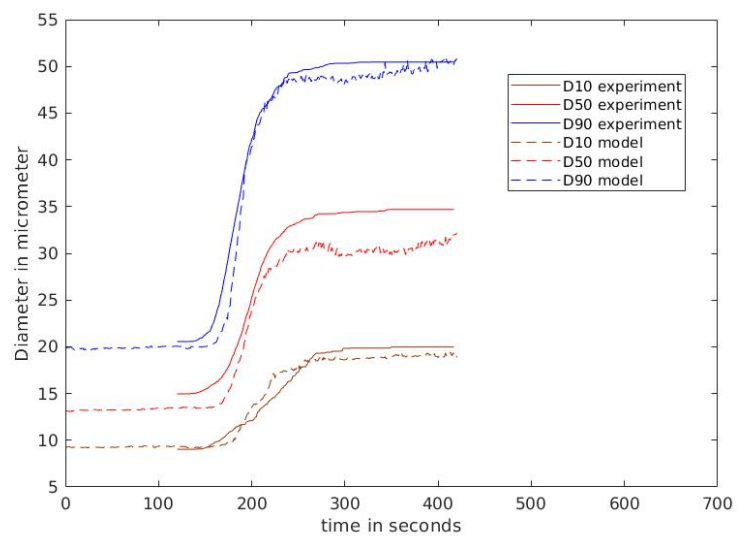

Case A

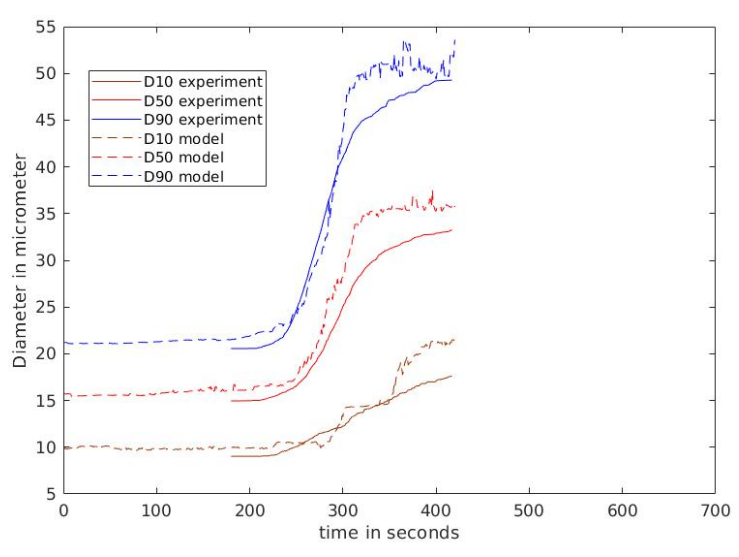

Case C

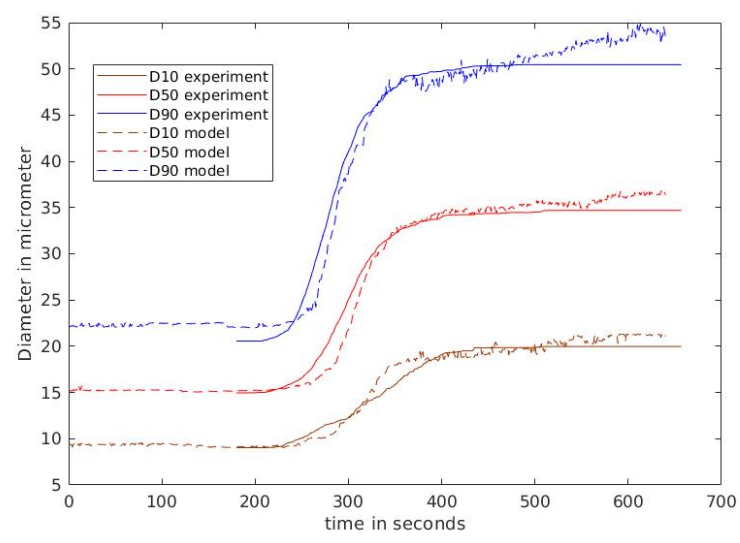

Case B

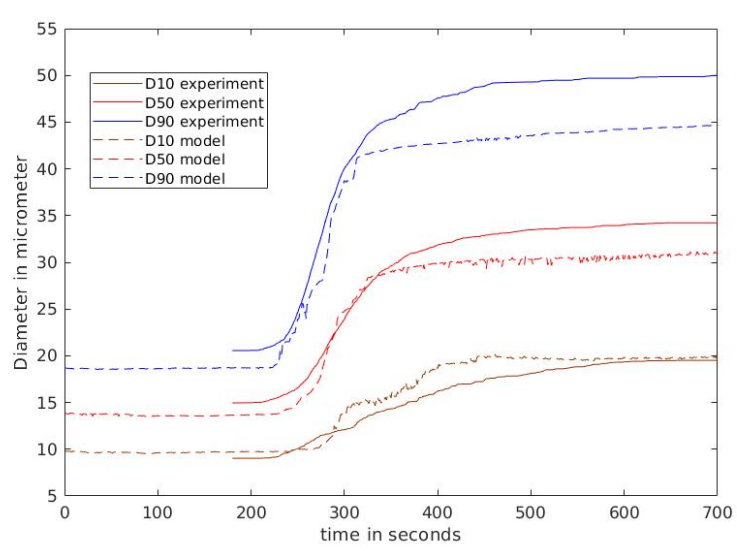

Case D

Figure 6: Model prediction of diameter evolution

of granule swelling in case A is twice compared to the same in case B. The rate of swelling is slower progressively with $D_{50}$ and $D_{10}$ compared to $D_{90}$ and this is more pronounced in the lower temperature cases $\mathrm{C}$ and $\mathrm{D}$. The deviation in case $\mathrm{D}$ can be attributed to the lower sample size and higher dispersion at lower temperatures. The latency time is lower for the higher ramp rate case A compared to the rest of the cases. Finally, both in the model and the experimental data the dispersion in size is higher after swelling compared to initial population.

Figure 7 presents the cumulative particle size distribution evolution at different time points as the starch granule swelling proceeds. The dashed curves and continuous are the 


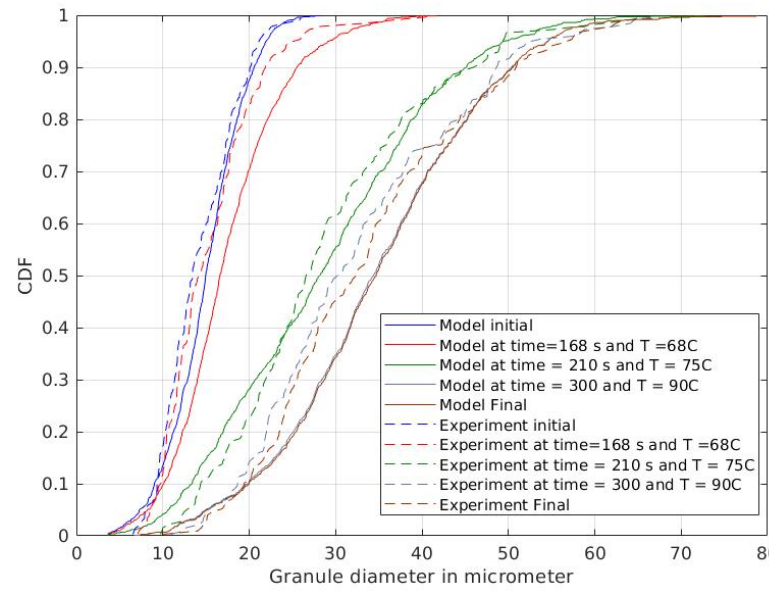

Particle size evolution with time Case A

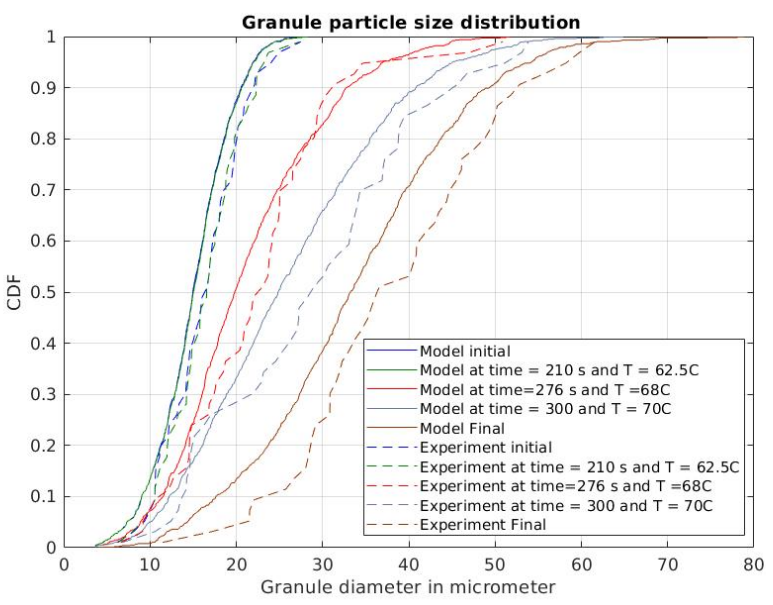

Particle size evolution with time Case C

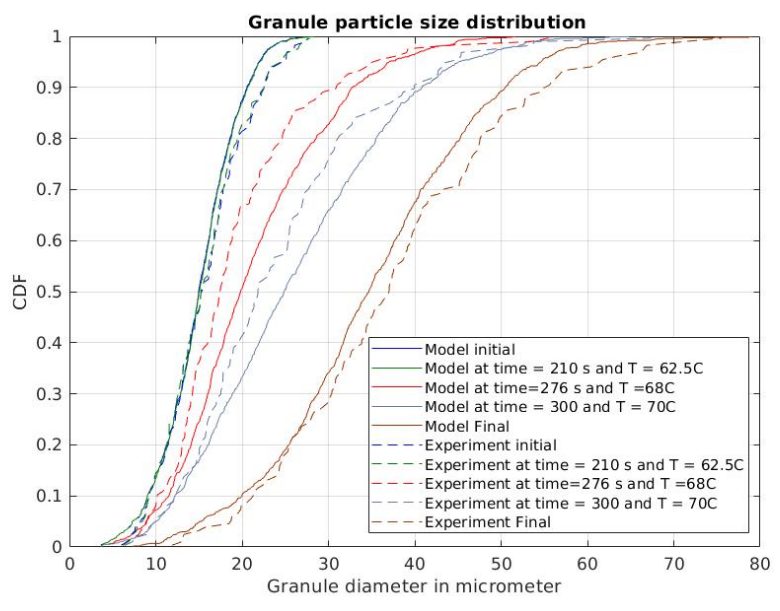

Particle size evolution with time Case B

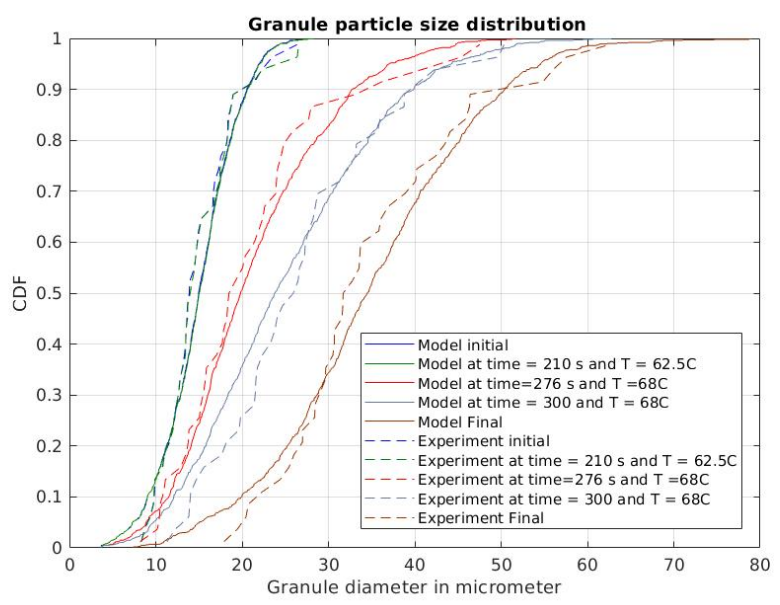

Particle size evolution with time Case D

Figure 7: Cumulative particle size distribution of different cases at different times and temperatures

experimentally observed and model predicted particle size distribution respectively. For both the simulation and experiment the curve at $68^{\circ} \mathrm{C}$ in case $\mathrm{A}$ is much closer to the initial one compared to the same temperature in case B. The difference can be attributed to the difference in latency times (median of 134 seconds vs 197 seconds). This means that not only temperature is important but also the temperature history together dictate the swelling of the starch granules. The relative good agreement between predicted and measured size distributions at intermediate starch swelling for different temperature evolution validate the applicability of the model. 


\subsection{Model application and validation}

In this section we make predictions using the developed model for the population swelling of the same starch using a completely different setup. Plana-Fattori et al. (2016) observed the volume size distributions of starch suspensions after different time-temperature histories using Malvern Mastersizer. The thermal treatment consisted of a series of three water baths, First the sample was immersed in a $50^{\circ} \mathrm{C}$ water bath until equilibrium was reached, then it was immersed into a water bath maintained at $92^{\circ} \mathrm{C}$. After specified "heating time" the sample was shifted to the third water bath maintained at $4^{\circ} \mathrm{C}$. All this while the bulk temperature of the sample was measured and noted at regular time intervals of 15 seconds.

For the sake of simplicity we only consider two cases with maximum temperature of $73^{\circ}$ $\mathrm{C}$ and $92^{\circ} \mathrm{C}$ respectively (figure $8 \mathrm{a}$ ). For simulation we only need the bulk temperature profiles above the cut off temperature of $60^{\circ} \mathrm{C}$. One should note that swelling can go on even during the cooling step as long as the temperature is above $60^{\circ} \mathrm{C}$.

Monte Carlo simulations using the same parameters mentioned in section 4.3 were performed. The difficulty of swelling parameter $(\alpha)$ and the maximum swelling ratio $\left(D_{f} / D_{i}\right)$ are first randomly chosen for each of 100,000 granules. Then the onset times are calculated according to equation (10) using piece-wise linear interpolation of the experimental temperature evolution. The swelling degree $(\mathrm{S})$ evolution are then calculated. The results of such simulations are shown in figure $8 \mathrm{~b}$ for the first case. Note that because of the decreasing temperature after about $90 \mathrm{~s}$ in the first case $\left(T_{\max }=73^{\circ} \mathrm{C}\right)$ the rate at which the granules swell decreases in figure 8b. This phenomenon is more evident for $\alpha$ between 0.75 and 0.99. Thus some of the granules are in a frozen state of partial swelling in line with the interpretations of Plana-Fattori et al. (2016) in this case.

From the diameters of the 1000 granules at the end of the heat treatment for both the cases, the volume size distributions were computed to be compared with results from Malvern Mastersizer assuming spherical particles. Initial diameters from the Malvern Mastersizer were used to perform the simulation. The experimental values and model predictions are overlaid in figure 8c. Overall a fairly good prediction is obtained by the model. However, there is discrepancy at lower particle sizes for $T_{\max }=73^{\circ} \mathrm{C}$. Considering the differences in the 


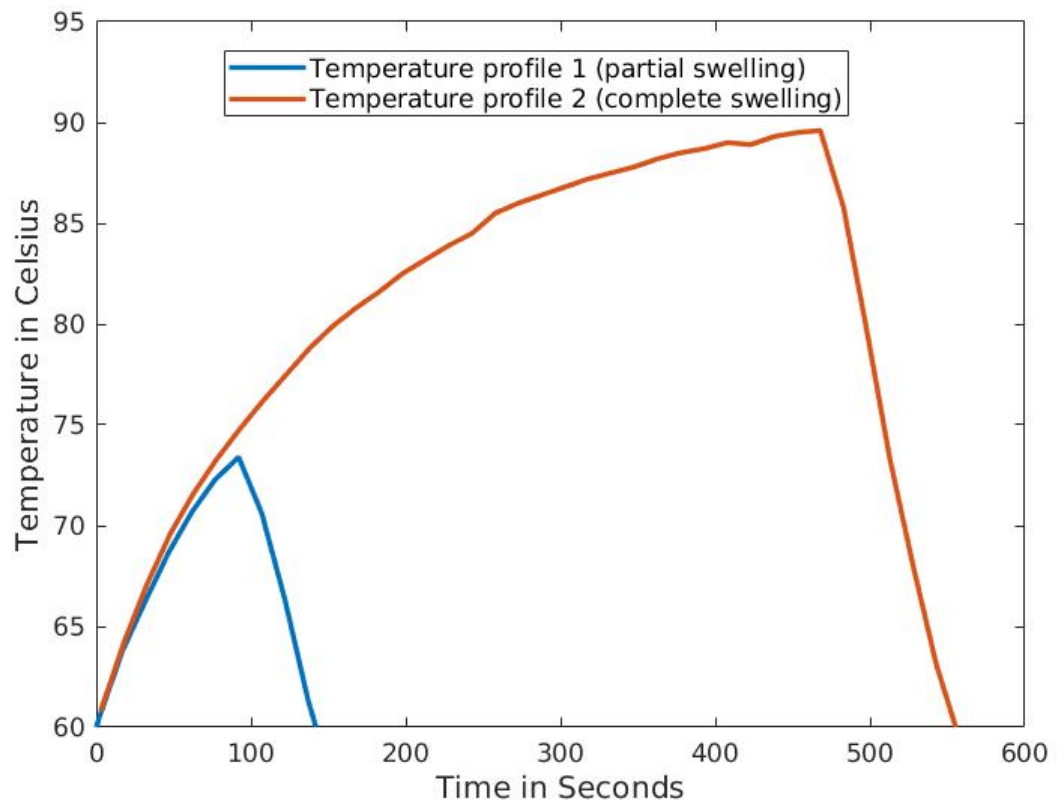

(a) Bulk Temperature profiles recorded for heating times of 2 minutes and 8 minutes (Courtesy of Plana-Fattori et al. (2016))

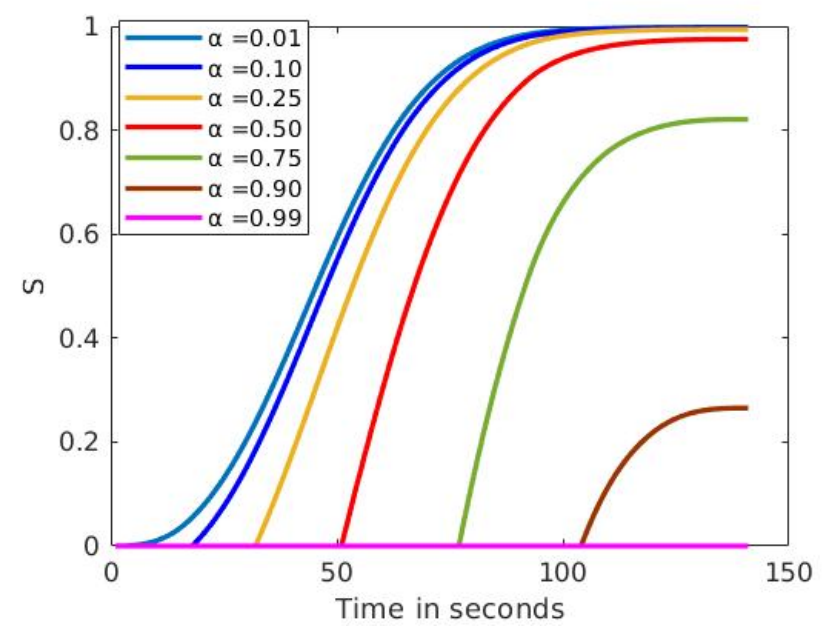

(b) Non-dimensional diameter evolution temperature profile 1

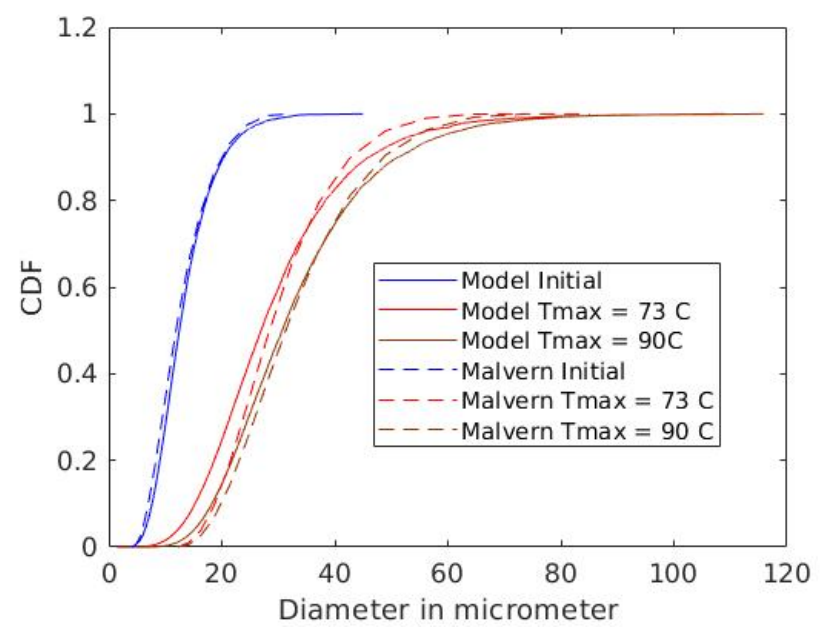

(c) Cumulative volume distribution

Figure 8

measuring techniques (microscopy for model fitting, light diffraction for Malvern) and various experimental and model assumptions (spherical particles, temperature uniform across the sample, $T_{\min }=60^{\circ} \mathrm{C}$ ) the performance of the model on a whole is good, notably to predict the size distribution of partially gelatinized starch which is of practical interest (Hickman et al., 2008). 


\subsection{Possible explanation of variability and model limitations}

The presented empirical model is based on individual granules observation and does not explain why different granules submitted to the same temperature evolution begin to swell at different instants $\left(t_{\text {onset }}\right)$ and with different swelling duration $(\Delta t)$. Literature suggests that various mechanisms are involved during starch swelling : melting of crystallites, moisture sorption, water diffusion, fusion of amylose/lipid complexes, leaching of amylose into the continuous phase, rupture of the granular structure (Briffaz et al., 2013, 2014; Chapwanya and Misra, 2015; Ozturk and Takhar, 2018). The three last phenomena do not occur in our case as waxy cross-linked maize starch was used for this work. In addition since we consider a very dilute system, there is no water availability limitation as discussed by Fukuoka et al. (2002).

Debet and Gidley (2006) identified three classes of starch granule swelling: (i) rapid swelling, (ii) slow swelling, (iii) limited swelling. For waxy maize starch there is no interaction between amylose, surface proteins and lipids and therefore rapid one-step swelling is observed. For other types of starch, the maximal swelling ratio can be function of the highest temperature reached. Indeed after a first swelling step (typically between 60 and $70{ }^{\circ} \mathrm{C}$ ), a second step (typically between 80 and $100{ }^{\circ} \mathrm{C}$ ) is observed, related to amylose/lipid/protein interaction for other types of starches (Briffaz et al., 2013). In our case, $D_{f} / D_{i}$ was found to be independent on the maximal temperature (for $T_{\max }>65^{\circ} \mathrm{C}$ ).

Melting of crystallites and moisture sorption can be affected by different parameters which can vary between granules such as crystallinity, branching of amylopectin, degree of cross linking, etc. (Debet and Gidley, 2006). This can explain variability in $t_{\text {onset }}$ and $\Delta t$ which was taken into account by a random parameter $\alpha$ (difficulty of swelling). One could expect that the 'difficulty of swelling' also influences the swelling ratio $D_{f} / D_{i}$, but no correlation was observed in our case between $D_{f} / D_{i}$ and $t_{\text {onset }}(\mathrm{p}$ value $\sim 0.95>>0.05)$.

Diffusion can be assumed as Fickian (based on water concentration gradient), non-Fickian (based on water demand) (Watanabe et al., 2001) or following Flory-Huggins theory (Desam et al., 2018, 2020). Tortuosity can be considered as function of aqueous volume fraction and can vary between granules depending on the amorphous/crystalline shell structure. If 
water availability is limited due to diffusion, the smallest granules should swell more rapidly. However, this was not observed in our case, there is no correlation between $D_{i}$ and $t_{\text {onset }}$, $\Delta t$ or $D_{f} / D_{i}$. It seems that in our case diffusion is not the limiting factor; different models were tested previously which confirmed that a diffusion based model is not pertinent for this kind of starch (Almeida et al., 2015).

To summarize, in our case (waxy cross-linked maize starch) variability in swelling onset and swelling duration could be attributed to the variability between granules in terms of crystallinity/structure, branching of amylopectin, cross linking. This variability comes perhaps from the different positions in the corn, positions on the cob, maturity, intra-granular heterogeneity, etc. These parameters influence the melting of the crystallites and the water diffusion. However, in our case the diffusion seems to not be the limiting phenomenon since the smallest granules do not swell faster than the biggest ones. It could be interesting to introduce variability for water activity curves and tortuosity in mechanistic swelling models such as the one developed by Desam et al. (2020). This approach could help one determine which of these parameters might potentially explain the swelling kinetics variability. For more complex starches (non-waxy or non-cross-linked) the presented model is perhaps not adapted and additional experimental efforts are required because additional phenomena occur

\section{Conclusion}

A novel individual granule scale model was developed to predict the swelling kinetics of modified waxy maize starch granules under heat treatment. The model parameters were calibrated with data from one ramp rate and hold temperature and validated with data from other cases. From the experiments it is shown that there is granule to granule variability not only in terms of ratio of swelling but also in terms of latency to swell when a critical temperature is reached. These phenomena are independent of the diameter of the granules. For practical time scales we can say the swelling reaction does not initiate below $60{ }^{\circ} \mathrm{C}$. The latency time is random with a characteristic time constant decreasing as temperature is increased. Also the kinetics of the reaction is enhanced at higher temperatures. A granule 
with high latency time is also shown to have slower swelling rate compared to granules with low latency time.

The rheology of the suspension results from the hydrodynamic interactions and collisions between the granules which is a function of the volume fraction of granules and granule PSD. To design, control, scale up and operate complex processes for liquid food products one needs to leverage simulation techniques such as Computational Fluid Dynamics (fluid flow, heat transfer) and Discrete Element Method (particle evolution and interaction). This granule scale model can represent the commencement of such techniques for multi-scale modelling and simulation of modified starch suspension undergoing thermal treatment.

\section{Acknowledgments}

This research has been carried out with funding from European Union as part of EU RESEARCH FRAMEWORK PROGRAMME: H2020 / Marie Skłodowska-Curie Actions ITN MATHEGRAM [813202].

We acknowledge Giana Almeida-Perré and Gabrielle Moulin (UMR-SayFood) for their support and contributions.

\section{References}

Almeida, G., Plana-Fattori, A., Moulin, G., Michon, C., and Flick, D. Observing and modeling the evolution of starch granules size distribution. In 6. International Symposium on Delivery of Functionality in Complex Food Systems. Physically-Inspired Approaches from the Nanoscale to the Microscale, 2015.

Anuntagool, J., Alvarez, G., and Flick, D. Predictive model for viscosity development of modified rice starch suspension under unsteady temperature change. Journal of Food Engineering, 209:45-51, 2017.

Ashogbon, A. O. and Akintayo, E. T. Recent trend in the physical and chemical modification of starches from different botanical sources: A review. Starch-Stärke, 66(1-2):41-57, 2014.

Atwell, W. The terminology and methodology associated with basic starch phenomena. Cereal Foods World, 33:306-311, 1988.

Bagley, E. and Christianson, D. Swelling capacity of starch and its relationship to suspension viscosity-effect of cooking time, temperature and concentration. Journal of Texture Studies, 13(1):115-126, 1982.

Bakshi, A. and Singh, R. Kinetics of water diffusion and starch gelatinization during rice parboiling. Journal of Food Science, 45:1387 - 1392, 1980. 
Banks, W., Greenwood, C., and Muir, D. Studies on starches of high amylose content. part 17. a review of current concepts. Starch-Stärke, 26(9):289-300, 1974.

Bertolini, A. C. Trends in starch applications. Starches: Characterization, Properties, and Applications. Taylor and Francis Group, LLC, Abingdon, 2010.

Biliaderis, C. G. and Prokopowich, D. J. Effect of polyhydroxy compounds on structure formation in waxy maize starch gels: a calorimetric study. Carbohydrate Polymers, 23(3):193-202, 1994.

Biliarderis, C. Structure and phase transitions of starch in food system. Food Technol., 46:98-109, 1992.

Blennow, A., Bay-Smidt, A. M., and Bauer, R. Amylopectin aggregation as a function of starch phosphate content studied by size exclusion chromatography and on-line refractive index and light scattering. International Journal of Biological Macromolecules, 28(5):409-420, 2001.

Briffaz, A., Mestres, C., Matencio, F., Pons, B., and Dornier, M. Modelling starch phase transitions and water uptake of rice kernels during cooking. Journal of Cereal Science, 58(3):387-392, 2013.

Briffaz, A., Bohuon, P., Méot, J.-M., Dornier, M., and Mestres, C. Modelling of water transport and swelling associated with starch gelatinization during rice cooking. Journal of food engineering, 121:143-151, 2014.

Chang, S.-M. and Liu, L.-C. Retrogradation of rice starches studied by differential scanning calorimetry and influence of sugars, nacl and lipids. Journal of Food Science, 56(2):564-566, 1991.

Chapwanya, M. and Misra, N. A soft condensed matter approach towards mathematical modelling of mass transport and swelling in food grains. Journal of Food Engineering, 145:37-44, 2015.

Chen, G., Campanella, O. H., and Purkayastha, S. A dynamic model of crosslinked corn starch granules swelling during thermal processing. Journal of Food Engineering, 81(2):500-507, 2007.

Choi, S.-G. and Kerr, W. L. Swelling characteristics of native and chemically modified wheat starches as a function of heating temperature and time. Starch-Stärke, 56(5):181-189, 2004.

Cui, L., Dong, S., Zhang, J., and Liu, P. Starch granule size distribution and morphogenesis in maize ('zea mays' l.) grains with different endosperm types. Australian Journal of Crop Science, 8(11):1560-1565, 2014.

Debet, M. R. and Gidley, M. J. Three classes of starch granule swelling: Influence of surface proteins and lipids. Carbohydrate Polymers, 64(3):452-465, 2006.

Desam, G. P., Li, J., Chen, G., Campanella, O., and Narsimhan, G. A mechanistic model for swelling kinetics of waxy maize starch suspension. Journal of Food Engineering, 222:237-249, 2018.

Desam, G. P., Li, J., Chen, G., Campanella, O., and Narsimhan, G. Swelling kinetics of rice and potato starch suspensions. Journal of Food Process Engineering, 43(4):e13353, 2020.

Deslandes, F., Plana-Fattori, A., Almeida, G., Moulin, G., Doursat, C., and Flick, D. Estimation of individual starch granule swelling under hydro-thermal treatment. Food Structure, 22:100125, 2019.

Dolan, K. D. and Steffe, J. F. Modeling rheological behavior of gelatinizing starch solutions using mixer 
viscometry data. Journal of Texture Studies, 21(3):265-294, 1990.

Doublier, J.-L., Llamas, G., and Le Meur, M. A rheological investigation of cereal starch pastes and gels. effect of pasting procedures. Carbohydrate Polymers, 7(4):251-275, 1987.

Evans, I. D. and Lips, A. Concentration dependence of the linear elastic behaviour of model microgel dispersions. Journal of the Chemical Society, Faraday Transactions, 86(20):3413-3417, 1990.

Fredriksson, H., Silverio, J., Andersson, R., Eliasson, A.-C., and Åman, P. The influence of amylose and amylopectin characteristics on gelatinization and retrogradation properties of different starches. Carbohydrate polymers, 35(3-4):119-134, 1998.

Fukuoka, M., Ohta, K.-i., and Watanabe, H. Determination of the terminal extent of starch gelatinization in a limited water system by DSC. Journal of Food Engineering, 53(1):39-42, 2002.

Hickman, B. E., Janaswamy, S., and Yao, Y. Properties of starch subjected to partial gelatinization and $\beta$-amylolysis. Journal of Agricultural and Food Chemistry, 57(2):666-674, 2008.

Hoover, R. Composition, molecular structure, and physicochemical properties of tuber and root starches: a review. Carbohydrate polymers, 45(3):253-267, 2001.

I'anson, K., Miles, M., Morris, V., Besford, L., Jarvis, D., and Marsh, R. The effects of added sugars on the retrogradation of wheat starch gels. Journal of Cereal Science, 11(3):243-248, 1990.

Kohyama, K. and Nishinari, K. Effect of soluble sugars on gelatinization and retrogradation of sweet potato starch. Journal of Agricultural and Food Chemistry, 39(8):1406-1410, 1991.

Kokini, J., Lai, L.-S., and Chedid, L. L. Effect of starch structure on starch rheological properties. Food Technology, 46:124-139, 1992.

Krüger, A., Ferrero, C., and Zaritzky, N. E. Modelling corn starch swelling in batch systems: effect of sucrose and hydrocolloids. Journal of Food Engineering, 58(2):125-133, 2003.

Kubota, K., Hosokawa, Y., Suzuki, K., and Hosaka, H. Studies on the gelatinization rate of rice and potato starches. Journal of Food Science, 44(5):1394-1397, 1979. doi: 10.1111/j.1365-2621.1979.tb06446.x.

Lagarrigue, S., Alvarez, G., Cuvelier, G., and Flick, D. Swelling kinetics of waxy maize and maize starches at high temperatures and heating rates. Carbohydrate Polymers, 73(1):148-155, 2008.

Lund, D. and Lorenz, K. J. Influence of time, temperature, moisture, ingredients, and processing conditions on starch gelatinization. C R C Critical Reviews in Food Science and Nutrition, 20(4):249-273, 1984.

Malumba, P., Jacquet, N., Delimme, G., Lefebvre, F., and Béra, F. The swelling behaviour of wheat starch granules during isothermal and non-isothermal treatments. Journal of Food Engineering, 114(2):199-206, 2013.

Malumba, P., Doran, L., Danthine, S., Blecker, C., and Béra, F. The effect of heating rates on functional properties of wheat and potato starch-water systems. LWT, 88:196-202, 2018.

MATLAB. version 9.4.0.813654 (R2018a). The MathWorks Inc., Natick, Massachusetts, 2018. 
Miles, M. J., Morris, V. J., Orford, P. D., and Ring, S. G. The roles of amylose and amylopectin in the gelation and retrogradation of starch. Carbohydrate research, 135(2):271-281, 1985.

Nayouf, M., Loisel, C., and Doublier, J. Effect of thermomechanical treatment on the rheological properties of crosslinked waxy corn starch. Journal of Food Engineering, 59:209-219, 2003.

Okechukwu, P. E. and Rao, M. A. Influence of granule size on viscosity of cornstarch suspension. Journal of Texture Studies, 26(5):501-516, 1995.

Okechukwu, P. E. and Rao, M. A. Kinetics of cowpea starch gelatinization based on granule swelling. Starch-Stärke, 48(2):43-47, 1996.

Ozturk, O. K. and Takhar, P. S. Water transport in starchy foods: Experimental and mathematical aspects. Trends in Food Science \& Technology, 78:11-24, 2018.

Plana-Fattori, A., Flick, D., Ducept, F., Doursat, C., Michon, C., and Mezdour, S. A deterministic approach for predicting the transformation of starch suspensions in tubular heat exchangers. Journal of Food Engineering, 171:28-36, 2016

Ratnayake, W. S. and Jackson, D. S. Starch gelatinization. Advances in Food and Nutrition Research, 55: 221-268, 2008.

Singh, J., Kaur, L., and McCarthy, O. Factors influencing the physico-chemical, morphological, thermal and rheological properties of some chemically modified starches for food applications - a review. Food Hydrocolloids, 21(1):1-22, 2007.

Slade, L. and Levine, H. A food polymer science approach to structure-property relationships in aqueous food systems: Non-equilibrium behavior of carbohydrate-water systems. In Water Relationships in Foods, pages 29-101. 1991.

Slade, L. and Levine, H. Glass transitions and water-food structure interactions. In Advances in Food and Nutrition Research, volume 38, pages 103-269. 1995.

Srichuwong, S., Sunarti, T. C., Mishima, T., Isono, N., and Hisamatsu, M. Starches from different botanical sources ii: Contribution of starch structure to swelling and pasting properties. Carbohydrate Polymers, 62(1):25-34, 2005.

Steeneken, P. Rheological properties of aqueous suspensions of swollen starch granules. Carbohydrate Polymers, 11(1):23-42, 1989.

Suzuki, U., Kubota, K., Omichi, M., and Hosaka, H. Kinetic studies on cooking of rice. Journal of Food Science, 41:1180 - 1183, 1976.

Szczesniak, A. S. Classification of textural characteristics a. Journal of Food Science, 28(4):385-389, 1963.

Tattiyakul, J. and Rao, M. A. Rheological behavior of cross-linked waxy maize starch dispersions during and after heating. Carbohydrate Polymers, 43(3):215-222, 2000.

Thomas, D. and Atwell, W. Eagan press handbook series: Starches. st. paul, minnesota, usa eagan press., 
1999.

Visser, R. G. F., Suurs, L. C. J. M., Steeneken, P. A. M., and Jacobsen, E. Some physicochemical properties of amylose-free potato starch. Starch-Stärke, 49(11):443-448, 1997.

Watanabe, H., Fukuoka, M., Tomiya, A., and Mihori, T. A new non-fickian diffusion model for water migration in starchy food during cooking. Journal of Food Engineering, 49(1):1-6, 2001.

Watanabe, H., Yahata, Y., Fukuoka, M., Sakiyama, T., and Mihori, T. The thermodynamic basis for the relative water demand model that describes non-fickian water diffusion in starchy foods. Journal of food engineering, 83(2):130-135, 2007.

Wood, F. W. Psychophysical studies on the consistency of liquid foods. Rheology and Texture of Food Stuffs, SCI Monograph, 27:40-49, 1968. 